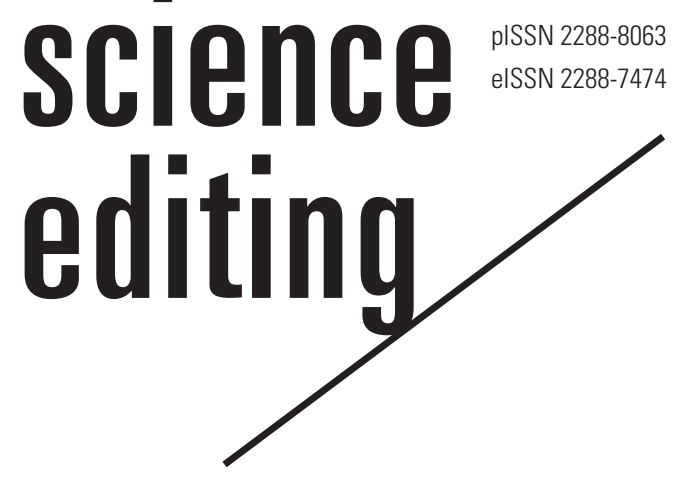

\title{
Comparison between Korean and foreign authors concerning the citation impact of Korean journals indexed in Scopus
}

\author{
Hyunju Jang ${ }^{1,2}$, Ki Woo Chun ${ }^{3,4}$, Hyungsun Kim ${ }^{5}$ \\ ${ }^{1}$ Graduate School of Business, Sungkyunkwan University, Seoul; ${ }^{2}$ Research Intelligence, Elsevier Korea, Seoul; ${ }^{3}$ Center for \\ R\&D Policy \& Innovation, National Research Foundation of Korea, Daejeon; ${ }^{4}$ College of Business, Korea Advanced Institute of \\ Science and Technology, Daejeon; ${ }^{5}$ Department of Materials Science \& Engineering, Inha University, Incheon, Korea
}

\begin{abstract}
Purpose: An aim of this study is to analyze the citation impact of articles and reviews that were published in engineering, materials science, and medical journals in Korea over the 5-year period from 2012 to 2016 based on authors' countries. These three subject areas were selected to provide insights regarding citation impact because they are better represented than other subjects among the 248 Korean journals indexed by Scopus.

Methods: We classified authors' as Korean and foreign to assess and compare the citation impact of articles and reviews according to the authors' countries and evaluated whether bibliometric indicators, such as the number of authors and the view count, were associated with a higher citation impact.

Results: We found that the citations count and publications in the top 10 citation percentile in these three subject areas were higher for reviews than for articles; further, the citation impact of articles and reviews by foreign authors was higher than that of articles and reviews by Korean authors. The number of authors had a weak relationship with citation impact based on the subject area, and the number of authors per review by foreign authors in materials science and medicine was negatively associated with citation impact. Moreover, the views count was found to be positively associated with the citation impact of publications in these three subject areas. Conclusion: Considering these findings, future research should explore more bibliometric indicators, subject areas, and countries in order to develop practical applications. The results of this study provide insights and statistical evidence indicating that journal publishers and editors in Korea should attempt to attract more publications by foreign authors and promote their publications to increase their visibility and likelihood of being cited.
\end{abstract}

Keywords

Bibliometrics; Citation; Publications; Republic of Korea; Research

This is an open access article distributed under the terms of the Creative Commons Attribution License (http://creativecommons.org/licenses/by/4.0/), which permits unrestricted use, distribution, and reproduction in any medium, provided the original work is properly cited. 


\section{Introduction}

According to the Korea Citation Index, 5,445 scholarly journals have been published in Korea [1]. Of these journals, 248 journals were indexed in Scopus as of May 2018. The number of articles and reviews published in Korean journals indexed in Scopus increased over the 5-year period from 2012 to 2016, with an annual growth rate of $4.6 \%$. Among the articles and reviews published in 248 Korean journals, $62.8 \%$ had Korean authors, followed by Chinese authors (12.2\%), authors from the United States (5.5\%), Indian authors (4.1\%), and authors from Iran (3.7\%). More foreign authors have published articles and reviews in Korean journals, according to a prior analysis indicating that $77.4 \%$ of articles in Korean journals were published by Korean authors [2]. It is likely that improved accessibility through various online databases such as the Web of Science, Scopus, PubMed, Google Scholar, and DOAJ (Directory of Open Access Journals) has increased the visibility of Korean journals, which may have led to more publications by foreign authors.

Along with the quantitative increase in the number of publications, previous research has addressed which bibliometric indicators lead to an increase in citations from a qualitative perspective. Because publishing high-quality research is fundamental to science, regularly evaluating the impact of publications is essential for scholarly journals and individual researchers [3]. As a qualitative evaluation indicator, the citation of publications determines the journal impact, which in turn shapes the number of publications. Furthermore, citations can be crucial for researchers' hiring and promotion decisions and for attracting high-quality papers to journals, although citation impact often depends on the subject area, journal index, and number of authors in co-authored publications. Citation impact also has been used as an assessment tool for parameters such as collaborative activity, engagement in various types of collaboration (e.g., international collaboration), open access, reference impact, abstract readability, and more $[4,5]$.

In this study, the relationship between research collabora- tion (i.e., the number of authors per publication) and view counts a form of usage data generated when requests are made for a publication on the Scopus site were investigated. Data on views were chosen because this parameter has implications for interest in research output and citation impact. We also sought to analyze and compare the citation impact of publications according to authors' countries. To investigate the latter, we examined information on authors' affiliations presented in articles and reviews. Groups of authors were classified as Korean or foreign based on the affiliation information presented in publications. If a Korean author was included in a publication for which foreign authors were predominant, the publication was classified as an article by foreign authors. The purpose of this paper is to provide comparative evidence on the citation impact of publications in engineering, materials science, and medical journals by Korean and foreign authors and identify the bibliometric indicators associated with the citation impact of the publications.

\section{Methods}

Among the 248 Korean journals indexed by Scopus, the three subject areas of engineering (46 titles), materials science (22 titles) and medicine (81 titles) were selected for analysis. The citation trends and patterns from these subject areas were expected to yield meaningful results since more journals are indexed by Scopus in these areas than in others. We chose a study period of 5-year from 2012 to 2016 and only examined articles and reviews. Our entire data set included 22,577 publications from the engineering field, 4,959 from materials science, and 25,957 from medicine. We evaluated the publications in each subject area using quantitative and qualitative indicators (Tables 1,2).

Our analytical strategy was to identify authors' affiliations and the number of authors and then assess the relationships of those parameters with citation impact. First, we extracted engineering, materials science, and medical journals published by Korean publishers and societies. Second, the dataset was limited to the parameters of publication type (article and re-

Table 1. Dataset description

\begin{tabular}{|c|c|c|c|c|c|c|c|}
\hline & Subject & 2012 & 2013 & 2014 & 2015 & 2016 & Overall \\
\hline \multirow[t]{3}{*}{ Article } & Engineering & 3,490 & 3,952 & 4,844 & 4,999 & 4,940 & 22,225 \\
\hline & Materials science & 887 & 937 & 941 & 1,032 & 1,085 & 4,882 \\
\hline & Medicine & 4,152 & 4,490 & 4,743 & 4,932 & 5,038 & 23,355 \\
\hline \multirow[t]{3}{*}{ Review } & Engineering & 108 & 65 & 59 & 51 & 69 & 352 \\
\hline & Materials science & 12 & 10 & 24 & 14 & 17 & 77 \\
\hline & Medicine & 741 & 652 & 566 & 615 & 948 & 3,522 \\
\hline
\end{tabular}


Table 2. Number of articles and reviews by authors' country of affiliation in three subject areas

\begin{tabular}{|c|c|c|c|c|c|c|c|c|c|c|c|c|c|c|c|c|c|c|}
\hline & \multicolumn{6}{|c|}{ Engineering } & \multicolumn{6}{|c|}{ Materials science } & \multicolumn{6}{|c|}{ Medicine } \\
\hline & Article & Review & Total & Article & Review & Total & Article & Review & Total & Article & Review & Total & Article & Review & Total & Article & Review & Total \\
\hline 2012 & 2,050 & 46 & 2,096 & 1,440 & 62 & 1,502 & 654 & 6 & 660 & 233 & 6 & 239 & 3,294 & 579 & 3,873 & 858 & 162 & 1,020 \\
\hline 2013 & 2,280 & 39 & 2,319 & 1,672 & 26 & 1,698 & 674 & 7 & 681 & 263 & 3 & 266 & 3,470 & 480 & 3,950 & 1,020 & 172 & 1,192 \\
\hline 2015 & 2,411 & 29 & 2,440 & 2,588 & 22 & 2,610 & 657 & 8 & 665 & 375 & 6 & 381 & 3,575 & 444 & 4,019 & 1,357 & 171 & 1,528 \\
\hline 2016 & 2,308 & 37 & 2,345 & 2,632 & 32 & 2,664 & 634 & 8 & 642 & 451 & 9 & 460 & 3,495 & 643 & 4,138 & 1,543 & 305 & 1,848 \\
\hline Total & 11,518 & 175 & 11,693 & 10,707 & 177 & 10,884 & 3,281 & 38 & 3,319 & 1,601 & 39 & 1,640 & 17,384 & 2,554 & 19,938 & 5,971 & 968 & 6,939 \\
\hline
\end{tabular}

view), year (2012-2016), and countries with which authors were affiliated (Korean and foreign). Third, based on authors' affiliations, publication type, and subject area, 12 groups were created (Table 2). Fourth, we analyzed research performance by publication type to identify citation trends according to authors' affiliations.

Comparisons between groups were conducted without statistical tests because all data from each group were collected. To determine whether the number of citations was affected by the number of authors in the 12 groups, a regression analysis was performed using IBM SPSS Ver. 20.00 (IBM Corp., Armonk, NY, USA).

\section{Results}

Comparison of the citation impact of publications between Korean authors and foreign authors

We identified authors' countries of affiliation from the dataset, and their distribution for authors of articles and reviews is shown in Fig. 1. For articles by foreign authors in engineering, China was the most common country of affiliation (37.7\%), followed by Iran (10.7\%) and the United States (9.9\%). For reviews in engineering, the percentage of authors from the United States was the highest (22.0\%), followed by Chinese authors (15.8\%) and Japanese authors (9.0\%). For articles in materials science, the percentage of Chinese authors was the highest (31.9\%), followed by Iranian (11.6\%) and Indian (8.1\%) authors. For reviews in materials science, the highest proportions of authors were from China (15.4\%), Malaysia (15.4\%), and the United States (15.4\%). In the area of medicine, authors from the United States accounted for the highest proportion of both articles and reviews written by foreign authors ( $17.5 \%$ and $39.9 \%$, respectively). Compared to engineering and materials science, the proportion of authors from the United States in medicine was quite high, which contributed to the citation impact.
As explained in the Methods section, we analyzed citations per publication and the publications in top 10 citation percentile to assess citation impact by publication type (article or review), authors' countries of affiliation (Korean and foreign), and subject areas (engineering, materials science, and medicine) (Tables 3, 4). Overall, the number of citations per publication by foreign authors was higher than the corresponding value for Korean authors by an average of 1.9, except for citations per review by Korean authors in materials science, which was 0.7 higher for reviews by foreign authors. Furthermore, the number of citations per review was generally higher than the number of citations per article except for citation per review by foreign authors in materials science. The number of citations per review by foreign authors in medicine was 13.8, which was the highest of the 12 groups analyzed, whereas the number of citations per article by Korean authors in engineering and materials science was relatively low (2.1 and 2.3, respectively). This finding shows that reviews received more attention from readers and researchers and more citations than articles. Citations per publication for medical subject were higher than for engineering and materials science for Korean authors, but this trend was not consistent for foreign authors in materials science.

As shown in Table 4, more articles by foreign authors than by Korean authors were in publications in top 10 citation percentile by $2.2 \%$ on an average in three subject areas. Reviews were more likely to be in the top 10 citation percentile than articles in engineering and medicine, while articles $(4.1 \%)$ by foreign authors was higher than reviews (2.6\%) in top 10 citation percentile for materials science. The following statistics support this trend. The percentage of reviews by foreign authors in medicine in the top 10 citation percentile was the highest $(25.8 \%)$, followed by reviews by Korean authors in medicine (16.0\%), reviews by foreign authors in engineering (11.3\%), and reviews by Korean authors in engineering (10.3\%). It is likely that reviews were more competitive than articles and that 

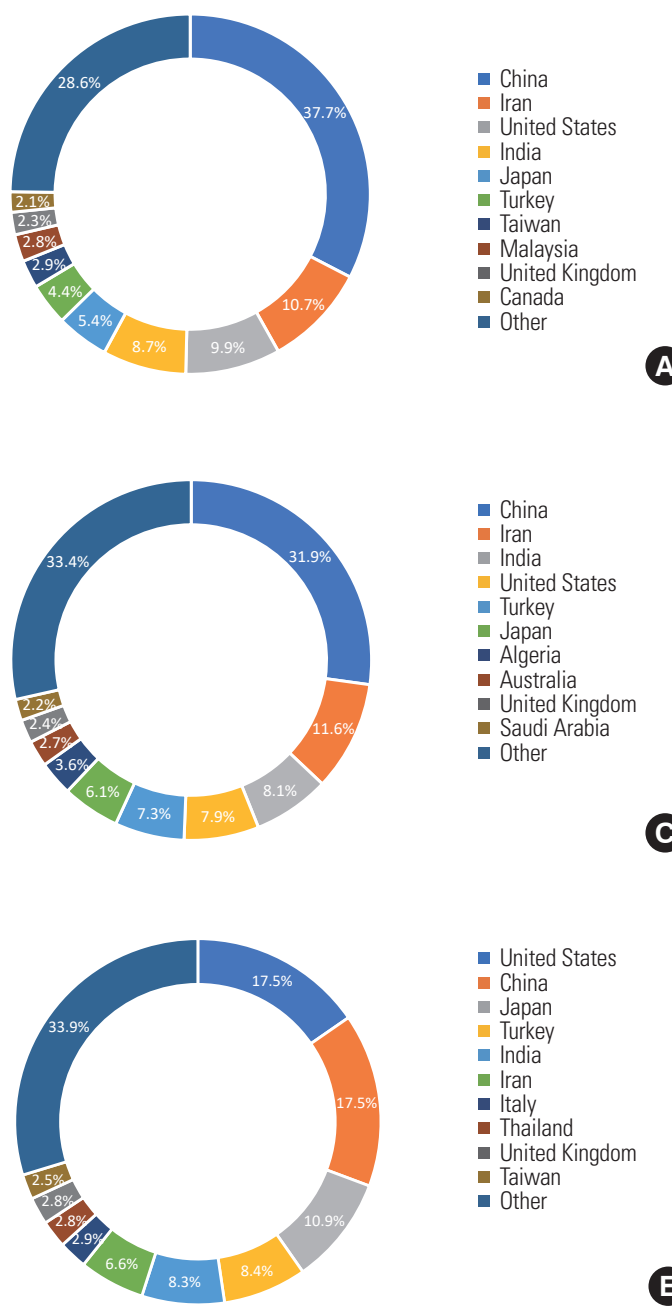

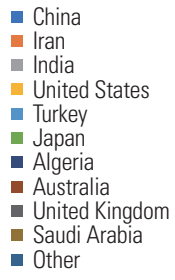

C

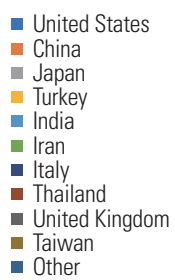

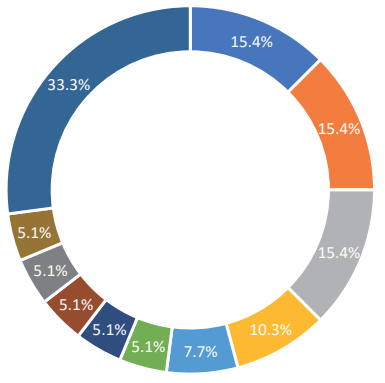

- China

- Malaysia

- United States

- Japan

- India

- Australia

- Canada

- France

- Italy

- United Kingdom

- Other
A

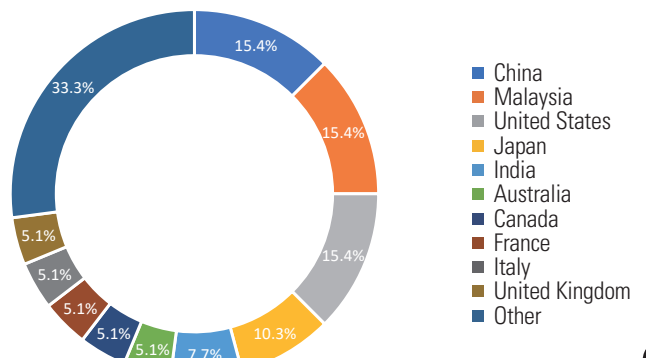

D

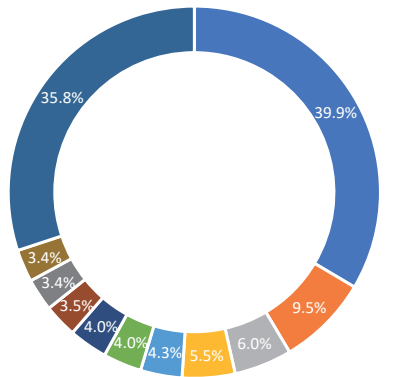

- United States

- Japan

- United Kingdom

- China

- Australia

- India

- Italy

- Germany

- Canada

- Taiwan

E
B

F

Fig. 1. Countries distribution ratio by authors group. (A) Article in engineering, (B) reviews in engineering, (C) articles in materials science, (D) reviews in materials science, (E) articles in medicine, and (F) reviews in medicine.

Table 3. Citations per publication by authors' country of affiliation in three subject areas

\begin{tabular}{|c|c|c|c|c|c|c|c|c|c|c|c|c|c|c|c|c|c|c|}
\hline & \multicolumn{6}{|c|}{ Engineering } & \multicolumn{6}{|c|}{ Materials science } & \multicolumn{6}{|c|}{ Medicine } \\
\hline & \multicolumn{3}{|c|}{ Korean } & \multicolumn{3}{|c|}{ Foreign } & \multicolumn{3}{|c|}{ Korean } & \multicolumn{3}{|c|}{ Foreign } & \multicolumn{3}{|c|}{ Korean } & \multicolumn{3}{|c|}{ Foreign } \\
\hline & Article & Review & Total & Article & Review & Total & Article & Review & Total & Article & Review & Total & Article & Review & Total & Article & Review & Total \\
\hline 2012 & 3.4 & 10.3 & 3.6 & 6.9 & 9.2 & 7.0 & 3.3 & 4.2 & 3.3 & 6.4 & 5.7 & 6.3 & 6.4 & 11.9 & 7.2 & 7.1 & 24.1 & 9.8 \\
\hline 2013 & 2.6 & 5.8 & 2.6 & 6.1 & 21.2 & 6.3 & 3.0 & 17.0 & 3.1 & 7.0 & 17.7 & 7.2 & 5.4 & 12.1 & 6.2 & 6.1 & 15.7 & 7.5 \\
\hline 2014 & 2.1 & 8.0 & 2.2 & 4.2 & 11.9 & 4.3 & 2.3 & 3.4 & 2.3 & 4.7 & 3.8 & 4.7 & 4.1 & 11.1 & 4.9 & 4.9 & 18.7 & 6.5 \\
\hline 2015 & 1.6 & 3.1 & 1.7 & 3.4 & 5.2 & 3.4 & 1.7 & 1.5 & 1.7 & 6.0 & 4.3 & 6.0 & 3.0 & 8.1 & 3.6 & 3.7 & 11.3 & 4.5 \\
\hline 2016 & 0.8 & 2.6 & 0.9 & 1.7 & 2.0 & 1.7 & 0.9 & 3.4 & 1.0 & 2.5 & 2.4 & 2.5 & 1.5 & 4.2 & 1.9 & 1.7 & 6.0 & 2.5 \\
\hline Total & 2.1 & 6.2 & 2.2 & 4.0 & 9.7 & 4.1 & 2.3 & 5.6 & 2.3 & 5.0 & 4.9 & 5.0 & 4.1 & 9.2 & 4.7 & 4.3 & 13.8 & 5.7 \\
\hline
\end{tabular}

publications by foreign authors were more competitive than those by Korean authors in terms of the citation index, but these trends showed variations across our dataset (Tables 3,4 ). 
Table 4. Output of papers in the top 10 percentile of citations by authors' country of affiliation in three subject areas

\begin{tabular}{|c|c|c|c|c|c|c|c|c|c|c|c|c|c|c|c|c|c|c|}
\hline & \multicolumn{6}{|c|}{ Engineering } & \multicolumn{6}{|c|}{ Materials science } & \multicolumn{6}{|c|}{ Medicine } \\
\hline & Article & Review & Total & Article & Review & Total & Article & Review & Total & Article & Review & Total & Article & Review & Total & Article & Review & Total \\
\hline 2012 & 0.5 & 10.9 & 0.8 & 2.2 & 6.5 & 2.3 & 0.0 & 0.0 & 0.0 & 0.4 & 0.0 & 0.4 & 1.3 & 9.5 & 2.6 & 2.3 & 21.6 & 5.4 \\
\hline 2013 & 0.3 & 7.7 & 0.4 & 1.9 & 26.9 & 2.3 & 0.4 & 28.6 & 0.7 & 2.7 & 0.0 & 2.6 & 1.7 & 12.9 & 3.1 & 1.6 & 18.6 & 4.0 \\
\hline 2016 & 1.0 & 16.2 & 1.3 & 4.1 & 6.3 & 4.1 & 1.3 & 12.5 & 1.4 & 7.1 & 11.1 & 7.2 & 3.2 & 20.7 & 5.9 & 4.7 & 28.9 & 8.7 \\
\hline Total & 0.6 & 10.3 & 0.7 & 2.5 & 11.3 & 2.7 & 0.5 & 7.9 & 0.6 & 4.1 & 2.6 & 4.1 & 2.0 & 16.0 & 3.8 & 3.1 & 25.8 & 6.2 \\
\hline
\end{tabular}

Values are presented as \%.

Table 5. Number of authors per publication by authors' country of affiliation in three subject areas

\begin{tabular}{|c|c|c|c|c|c|c|c|c|c|c|c|c|c|c|c|c|c|c|}
\hline & \multicolumn{6}{|c|}{ Engineering } & \multicolumn{6}{|c|}{ Materials science } & \multicolumn{6}{|c|}{ Medicine } \\
\hline & Article & Review & Total & Article & Review & Total & Article & Review & Total & Article & Review & Total & Article & Review & Total & Article & Review & Total \\
\hline 2012 & 3.6 & 1.9 & 3.5 & 3.3 & 2.8 & 3.3 & 4.1 & 2.7 & 4.1 & 4.0 & 5.5 & 4.0 & 6.0 & 3.4 & 5.6 & 5.3 & 3.4 & 5.0 \\
\hline 2013 & 3.4 & 2.2 & 3.3 & 3.4 & 3.2 & 3.3 & 3.9 & 3.7 & 3.9 & 4.1 & 2.3 & 4.1 & 5.9 & 3.0 & 5.6 & 5.5 & 3.2 & 5.2 \\
\hline 2015 & 3.4 & 3.4 & 3.4 & 3.4 & 4.0 & 3.4 & 4.0 & 3.1 & 4.0 & 3.9 & 4.8 & 3.9 & 6.1 & 3.4 & 5.8 & 5.7 & 3.3 & 5.5 \\
\hline 2016 & 3.4 & 2.6 & 3.4 & 3.5 & 3.6 & 3.5 & 3.9 & 2.3 & 3.9 & 4.0 & 3.4 & 4.0 & 6.2 & 3.3 & 5.7 & 5.9 & 3.4 & 5.5 \\
\hline Total & 3.4 & 2.4 & 3.4 & 3.4 & 3.4 & 3.4 & 4.0 & 3.1 & 4.0 & 4.0 & 4.5 & 4.1 & 6.0 & 3.2 & 5.7 & 5.6 & 3.3 & 5.3 \\
\hline
\end{tabular}

Citation impact and the number of authors

From the perspective of research collaboration, more authors contributing to an article should lead to more traffic, thereby increasing opportunities for citation. Many studies have shown that research collaboration, as indicated by co-authorship, is essential for progress in scientific research. Over the past several decades, large-scale collaborative projects have become increasingly frequent in fields as diverse as high-energy physics, medicine, and genetics [6-8]. Although these large collaborations have received the lion's share of media attention [9], research collaboration on a smaller scale is also important for scientific productivity and influence [10]. For instance, within the field of bibliometrics, the total number of co-authors of a publication is positively correlated with the number of citations received by that study [11].

We investigated the number of authors per publication and the citation impact of publication in three subject areas (engineering, materials science, and medicine) by publication type (articles and reviews) and country of affiliation of the authors (Korean or foreign). Generally, articles had more authors than reviews, except for reviews by foreign authors in engineering.
In all three subject areas, the number of authors per review by foreign authors was larger than the number of authors per review by Korean authors. The difference in the number of authors per review between Korean and foreign authors was 1, 1.4 , and 0.1 for engineering, materials science, and medicine, respectively (Table 5). In contrast, the number of authors per article was the same for Korean and foreign authors in engineering (3.4) and materials science (4.0), and the number of authors per article by Korean authors in medicine was higher than the corresponding value for foreign authors by 0.4 . In medicine, the number of authors per article and review by Korean authors was larger than for articles and reviews by foreign authors (Table 5).

As shown in Fig. 2, there was a weak relationship between the number of authors per publication and citation impact. The number of authors per review by Korean authors in engineering and the number of authors per review by foreign authors in materials science showed a slight association with citation impact. Interestingly, the number of authors per review by foreign authors in materials science and medicine was negatively associated with citation impact (Fig. 2). 

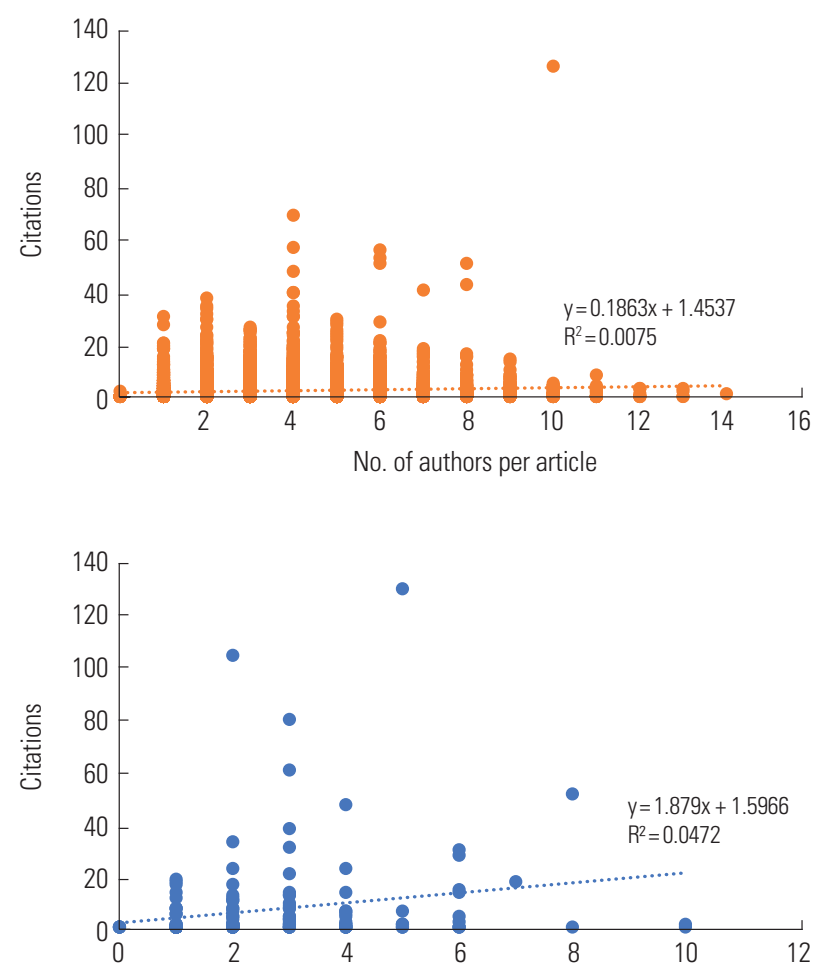

No. of authors per review

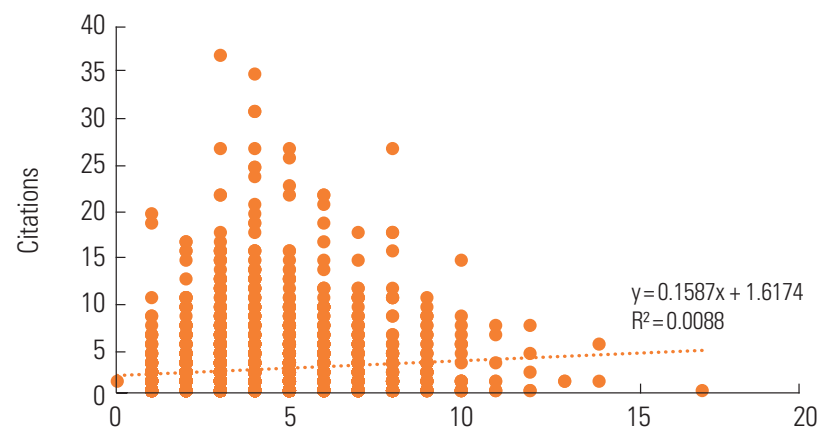

No. of authors per article

E

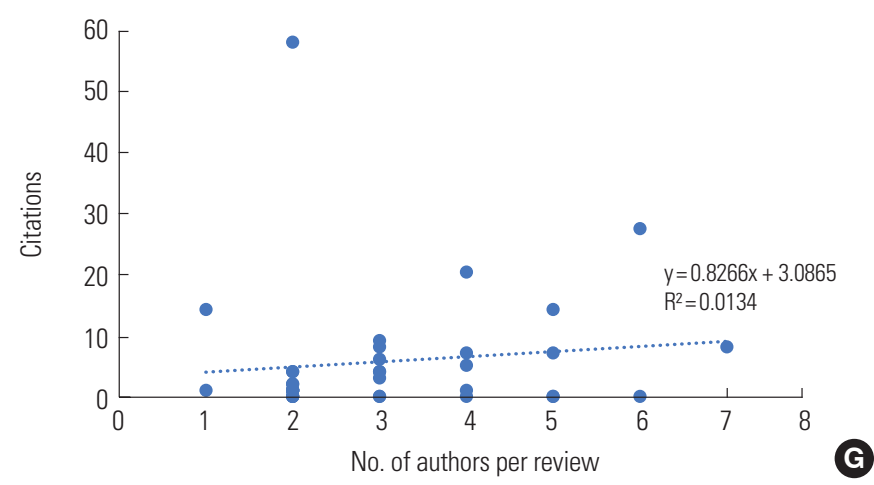

A

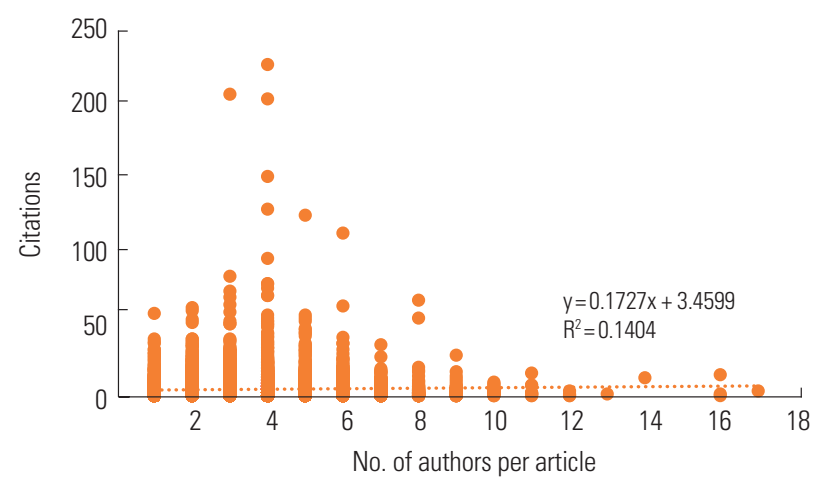

B

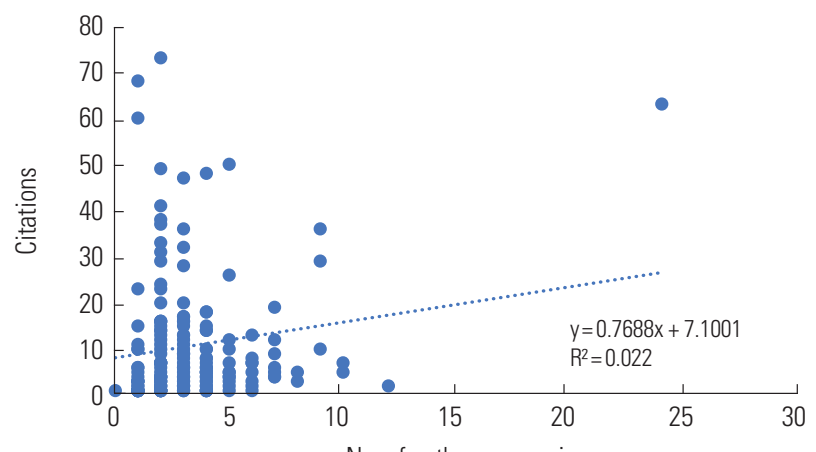

D

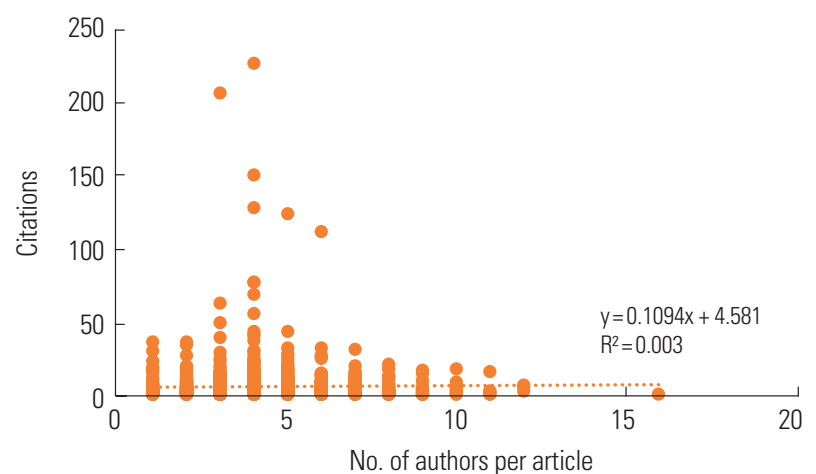

$\boldsymbol{F}$

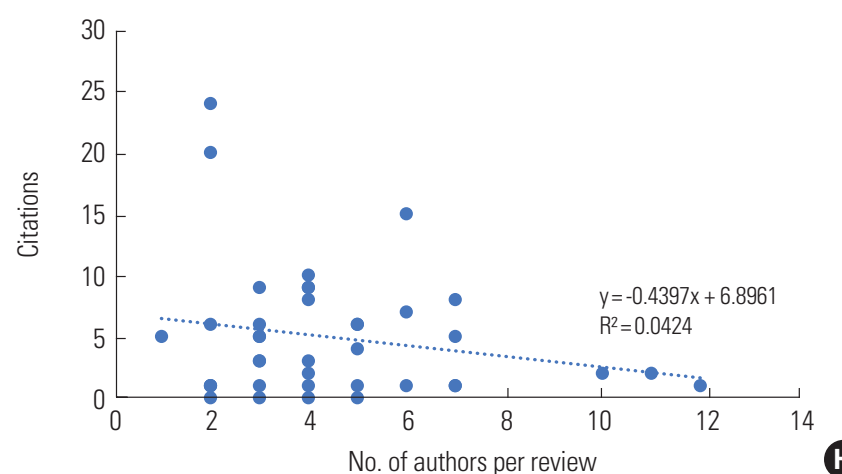

Fig. 2. (Continued to the next page) 

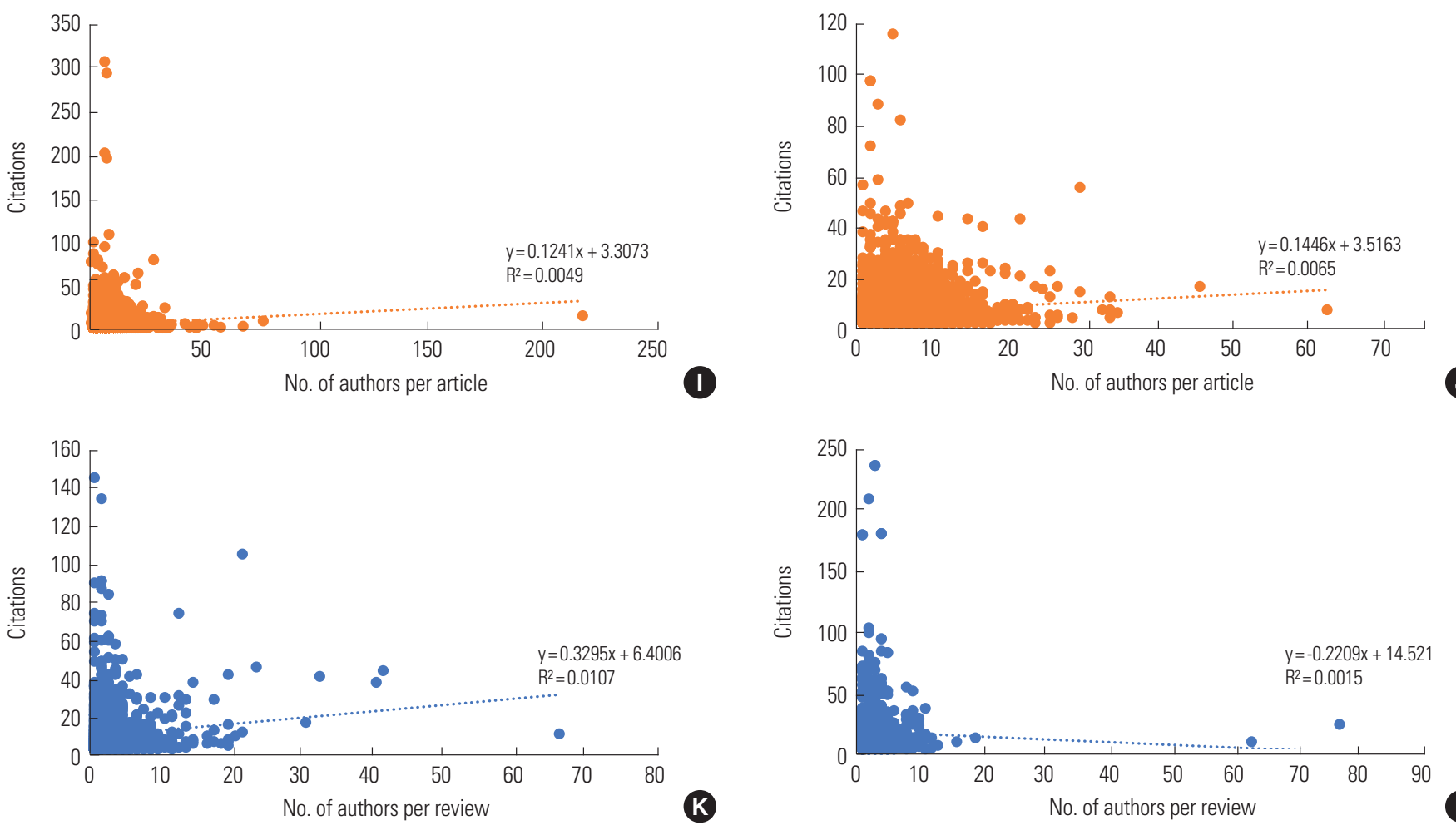

Fig. 2. (Continued) Relationship between No. of authors per publication and citations by author group in three subjects. (A) Articles by Korean author group in engineering, (B) articles by foreign author group in engineering, (C) reviews by Korean author group in engineering, (D) reviews by foreign author group in engineering, (E) articles by Korean author group in materials science, (F) articles by foreign author group in materials science, (G) reviews by Korean author group in materials science, $(\mathrm{H})$ reviews by foreign author group in materials science, (I) articles by Korean author group in medicine, (J) articles by foreign author group in medicine, $(\mathrm{K})$ reviews by Korean author group in medicine, and $(\mathrm{L})$ reviews by foreign author group in medicine.

Table 6. Views count per publication by authors' country of affiliation in three subject areas

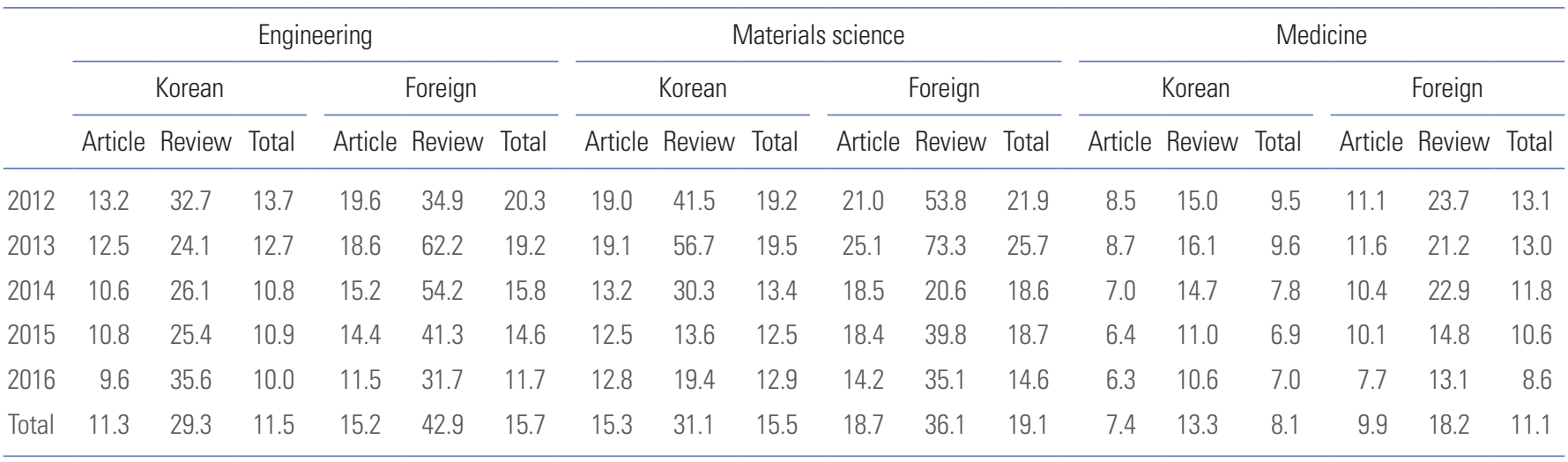

Citation impact and view count per publication

Since scholarly publications are published and distributed through various online sources, several previous studies have addressed the importance of downloads and views count; researchers have attempted to measure scientific impact based on these parameters. Such data would allow scientific activities to be measured immediately after publication, rather than having to wait for citations. Previous studies have proposed the "download impact factor" as a journal metric $[12,13]$ reporting close correlations between citations and downloads [14].

In the present study, we extracted the record of clicks from the Scopus data on download usage and analyzed whether the views count was associated with citations of publications 

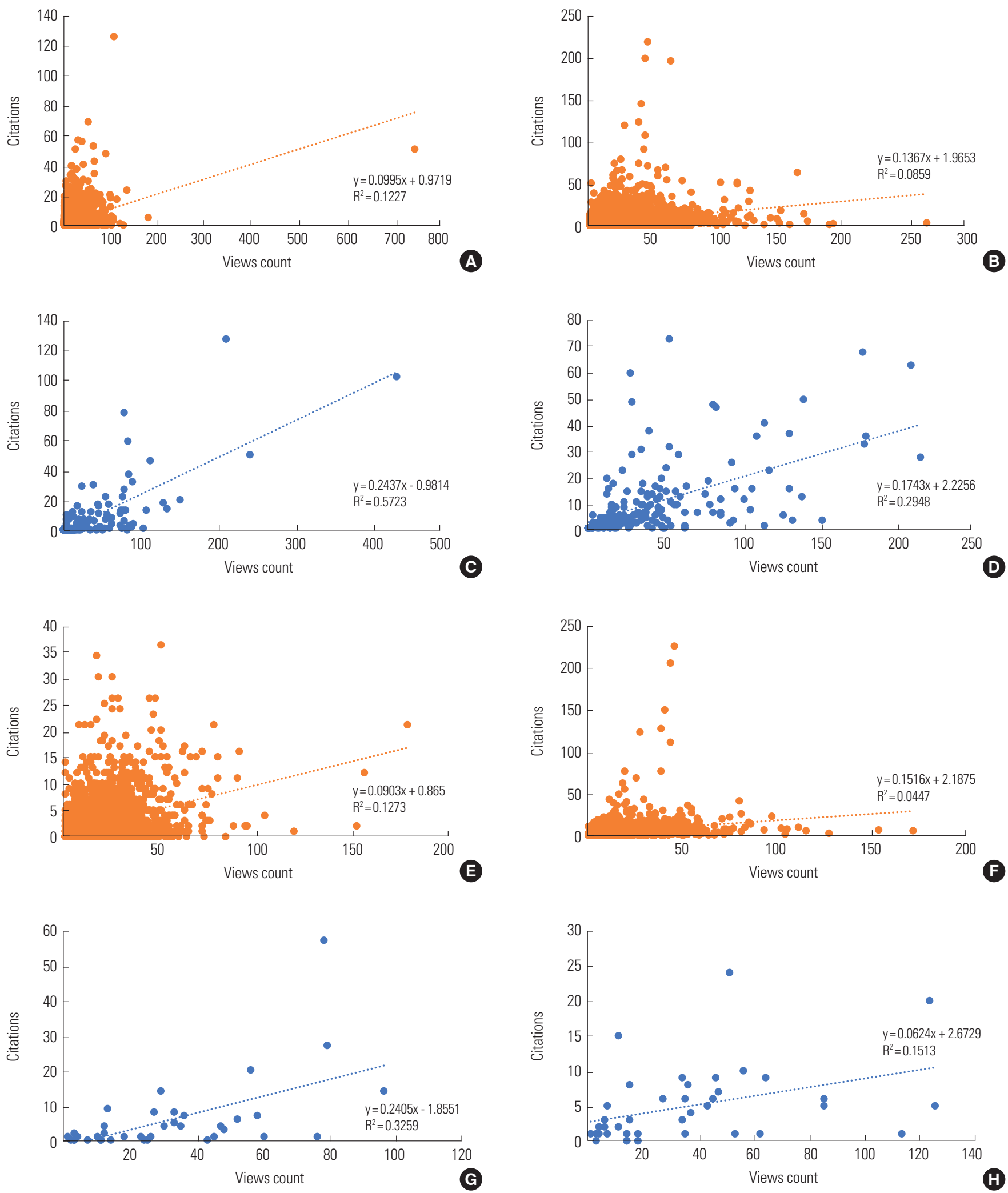

Fig. 3. (Continued to the next page) 

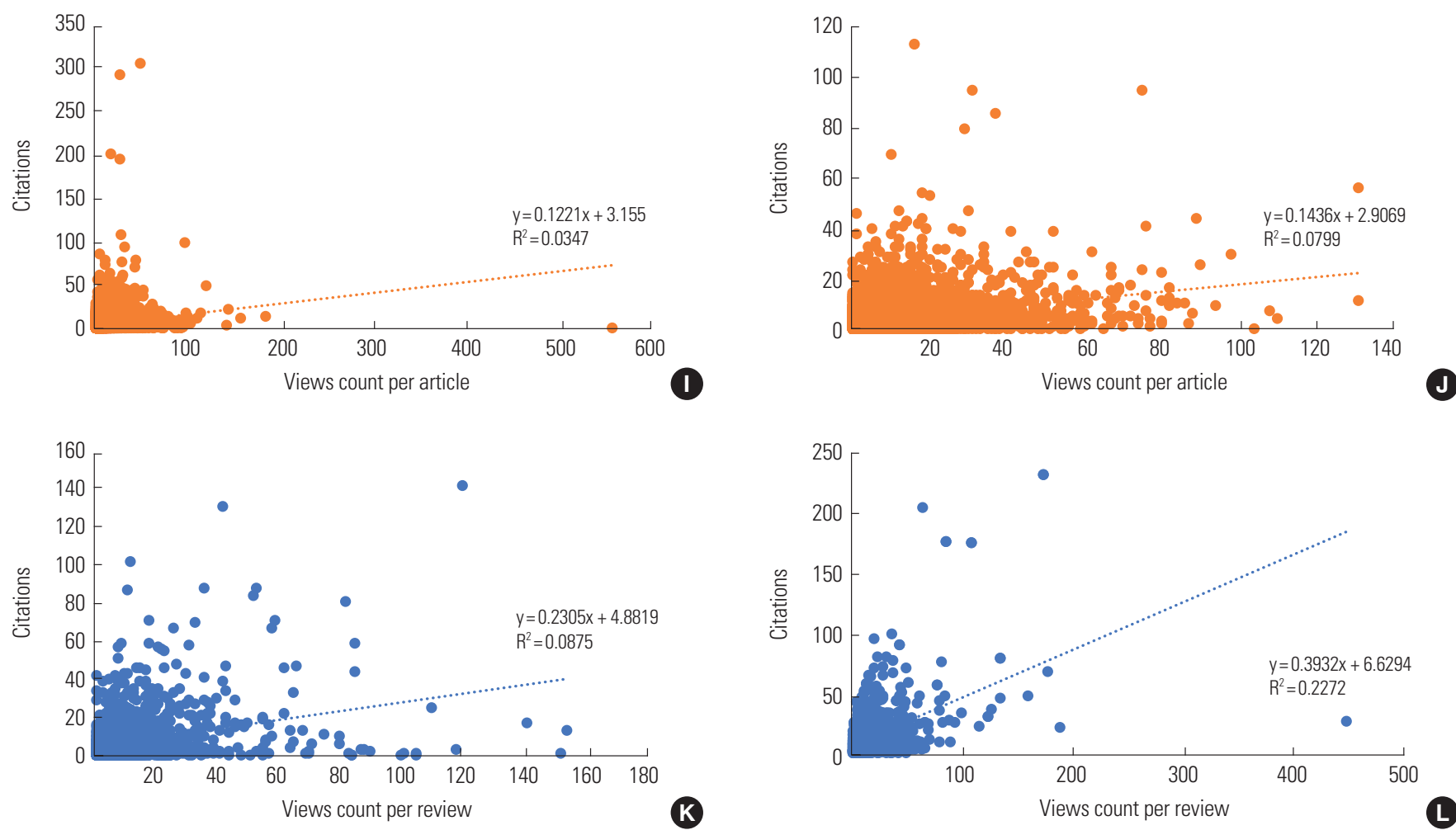

Fig. 3. (Continued) Relationship between views count per publication and citations by author group in three subjects. (A) Articles by Korean author group in engineering, (B) articles by foreign author group in engineering, (C) reviews by Korean author group in engineering, (D) reviews by foreign author group in engineering, (E) articles by Korean author group in materials science, (F) articles by foreign author group in materials science, (G) reviews by Korean author group in materials science, $(\mathrm{H})$ reviews by foreign author group in materials science, (I) articles by Korean author group in medicine, (J) articles by foreign author, group in medicine, (K) reviews by Korean author group in medicine, and (L) reviews by foreign author group in medicine.

across our 12 different categories. We found two trends in the views count analysis. First, the view count of publications by foreign authors was higher than that for publications by Korean authors (by an average of 7.6). This result was in all three subject areas (Table 6). The views count per review by foreign authors in engineering was highest (42.9), and the views count for reviews (on average, 15.5) was higher than the views count per article. The difference between views count per article and per review was highest in publications by foreign authors in engineering (27.7), whereas it was relatively small for Korean authors writing on medical subject (6.0).

How is views count important in terms of citation impact? To provide an answer to this question, we analyzed the relationship between views count and citation impact across the 12 groups of publications (Fig. 3). There was a relatively strong relationship between views count per publication and citation impact compared to the number of authors per publication. In particular, views count per review by Korean authors in engineering and materials science and by foreign authors in engineering and medicine was strongly associated with citation impact. This finding underscores that views count per review rather than views count per article is more closely related to citation impact.

\section{Discussion}

In this study, the citation impact of articles and reviews published by Korean and foreign authors in Korean journals in engineering, materials science, and medicine was examined, with the goal of determining whether bibliometric indicators, such as the number of authors and views count, affected citations of the publication. We found that citations and the publications in top 10 citation percentile in three subject areas were higher for reviews than for articles, except for reviews by foreign authors in materials science. In particular, citations and publications in top 10 citation percentile for reviews in engineering and medicine were quite high. The citation impact of articles and reviews by foreign authors was higher than that for articles and reviews by Korean authors, except for reviews by Korean authors in materials science. The number of authors per review by foreign authors was larger than the number of authors per review by Korean authors, and ar- 


\section{science editing /}

ticles in medicine had more authors than those in other subject areas.

Authors from the United States accounted for a large percentage $(39.9 \%)$ of the reviews in medicine since journal publishers and editors routinely invite distinguished researchers to write reviews. The high percentage of authors from the United States contributed to the higher number of citations and publications in top 10 citation percentile for reviews in medicine. This finding suggests that inviting foreign authors to write reviews is a successful approach in terms of citation impact. The lower citation impact of reviews by foreign authors rather than by Korean authors in materials science can be interpreted as indicating that, world-wide, top-ranking researchers in Korea were invited to submit review in their specific fields. Materials science is known to be one of the most competitive research areas in Korea from a global perspective, as shown by the fact that the number of publications was third and the field-weighted citation impact was 1.38 , which was the fourth-highest of 22 categories in Korea [15].

Globally, the publication share of authors from the United States, China, India and Japan was reported to be $25 \%, 22 \%$, $5.4 \%$, and $5 \%$, respectively, based on a Department for Business, Energy and Industrial Strategy report [16]. This pattern is consistent with that shown in Korean journals, although authors from Malaysia, Iran, and Turkey are relatively overrepresented in Korean journals because of their willingness to submit articles to Korean journals since original articles are considered voluntary in terms of publishing activities unlike reviews.

There was a weaker relationship between the number of authors per publication and citation impact. This trend depended on subject area, as the number of authors per review by foreign authors in materials science and medicine was negatively associated with citation impact. There was a positive relationship between views count per publication and citation impact. As the view count increased, the citation impact increased because the publication had more opportunities to be cited. Additionally, this effect of views count seemed to be higher for reviews than for articles.

The limitations of this study include the classification of authors and bibliometric indicators. If a Korean author contributed to a publication along with foreign researchers, the publication was classified as having foreign authors, which means that there were more publications reflecting international collaboration than publications involving national and institutional collaboration $[5,17,18]$.To identify additional bibliometric indicators that could be important for increasing the citation impact of articles and reviews, future research could extend our research methodology to cover more bibliometric indicators and journals published by Asian countries in order to validate whether the findings we reported for Korean journals can be generalized.

Our findings imply that journal publishers and editors in Korea should attract more reviews by foreign authors, which are positively associated with increased citations. Doing so will help increase journal impact. Views count and citation impact were found to be positively associated. Hence, journal publishers and editors should support collaborative work, invite more publications from international authors, and promote their publications to increase view count, which is helpful for increasing opportunities to be cited and for promoting the visibility of research.

\section{Conflict of Interest}

No potential conflict of interest relevant to this article was reported.

\section{References}

1. Korea Citation Index. KCI statistics [Internet]. Daejeon: National Research Foundation of Korea; 2018 [cited 2018 Apr 30]. Available from: https://www.kci.go.kr/kciportal/ po/statistics/poStatisticsMain.kci

2. Jang H, Kim K, Huh S, Kim H. Increasing number of authors per paper in Korean science and technology papers. Sci Ed 2016;2:80-9. https://doi.org/10.6087/kcse.70

3. Chang CL, McAleer M, Oxley L. How are journal impact, prestige and article influence related? An application to neuroscience. J Appl Stat 2011;11:2563-73. https://doi.org/ 10.1080/02664763.2011.559212

4. Bornmann L, Mutz R, Daniel HD. Are there better indices for evaluation purposes than the $\mathrm{h}$ index? A comparison of nine different variants of the $\mathrm{h}$ index using data from biomedicine. J Am Soc Inf Sci Technol 2008;59:830-7. https://doi.org/10.1002/asi.20806

5. Didegah F, Thelwall M. Which factors help authors produce the highest impact research? Collaboration, journal and document properties. J Inf 2013;7:861-73. https://doi. org/10.1016/j.joi.2013.08.006

6. Ioannidis JP. Measuring co-authorship and networkingadjusted scientific impact. PLoS One 2008;7:e2778. http:// dx.plos.org/10.1371/journal.pone.0002778

7. Cummings JN, Kiesler S. Collaborative research across disciplinary and organizational boundaries. Soc Stud Sci 2005; 35:703-22. https://doi.org/10.1177/0306312705055535

8. CERN. The Large Hadron Collider [Internet]. Geneva: CERN; 2018 [cited 2018 Apr 26]. Available from: http:// home.cern/topics/large-hadron-collider

9. Sarkar M. Large Hadron Collider: world's biggest physics 
experiment restarts [Internet]. Atlanta, GA: CNN; 2015 [cited 2018 Apr 26]. Available from: http://www.cnn.com/ 2015/04/05/europe/hadron-collider-restart/

10. Katz JS, Martin BR. What is research collaboration?. Res Policy 1997;26:1-18. https://doi.org/10.1016/S0048-7333 (96)00917-1

11. Huang MH, Wu LL, Wu YC. A study of research collaboration in the pre-web and post-web stages: a coauthorship analysis of the information systems discipline. J Assoc Inf Sci Technol 2015;66:778-97. http://doi.wiley.com/10.1002/ asi.23196

12. Shepherd PT. The feasibility of developing and implementing journal usage factors: a research project sponsored by UKSG. Serials 2007;20:117-23.

13. Bollen J, van de Sompel H, Rodriguez MA. Towards usage-based impact metrics: first results from the MESUR project. Paper presented at: 2008 Joint Conference on Digital Libraries; 2008 Jun; Pittsburgh, PA, USA.

14. Schlogl C, Gorraiz J, Gumpenberger C, Jack K, Kraker P. Comparison of downloads, citations and readership data for two information systems journals. Scientometrics 2014; 101:1113-28. https://doi.org/10.1007/s11192-014-1365-9

15. Elsevier Korea. Research trends \& performance 2015 [Internet]. Seoul: Elsevier Korea; 2015 [cited 2018 Apr 26]. Available from: http://korea.elsevier.com/koreamailings/ ADM/Down/Alex/RTP/RTP\%20Vol\%207_Final.pdf

16. Department for Business, Energy \& Industrial Strategy. International comparative performance of the UK research base 2016 [Internet]. [place unknown]: Department for Business, Energy \& Industrial Strategy; 2017 [cited 2018 Apr 26]. Available from: https://www.elsevier.com/_data/ assets/pdf_file/0018/507321/ELS-BEIS-Web.pdf

17. Andrew B. Rosenkrantz, Ujas Parikh, Richard Duszak. Citation impact of collaboration in radiology research. J Am Coll Radiol 2018;15:258-61. https://doi.org/10.1016/j.jacr. 2017.09.030

18. Nomaler O, Frenken K, Heimeriks G. Do more distant collaborations have more citation impact?. J Inf 2013;7: 966-71. https://doi.org/10.1016/j.joi.2013.10.001 